\title{
Gebelik ve Emzirme Döneminde Yakın Eş Şiddetinin Maternal/Fetal Sağlığa ve Beslenmeye Etkileri
}

\author{
The Effects of Intimate Partner Violence on Maternal/Fetal Health and Nutrition during \\ Pregnancy and Lactation
}

\author{
Asghar Amanpour ${ }^{1}$, Ezgi Ertal ${ }^{2}$, Seda Nur Yıldız ${ }^{3}$, Fatma Çelik ${ }^{4}$
}

Geliş tarihi/Received: 01.10.2020 • Kabul tarihi/Accepted: 28.12.2020

\section{ÖZET}

Şiddet, en az insanlık tarihi kadar eski olmasına rağmen, özellikle son yüzyıla kadar ciddi bir sorun olarak algılanmamıştır. Ancak değişik nedenlerle her gün artarak yaşanılan ve günlük hayata neredeyse yerleşme boyutuna gelen şiddet, bireysel şiddetten kolektif şiddete her boyutta ortaya çıkmaktadır. Her yıl bir milyondan fazla kişi, uygulanan şiddet sonucu hayatını kaybetmektedir. Gebelik, özellikle de planlanmamış bir gebelik ise aile içi şiddet için önemli bir risktir. Gebelik sırasında aile içi şiddet, özellikle düşük gelirli ülkelerde önemli bir halk sağlığı sorunu olarak rapor edilmektedir. Gebelik döneminde yakın eş şiddeti, hem gebelik hem de emziklilik döneminde anne ve çocuktaki beslenme ve sağlık sorunları ile yakından ilişkilidir. Raporlar, gebelikte bazı sağlık sorunları ile birlikte obstetrik komplikasyonlar, psikolojik sorunlar, erken doğum, fetal büyüme geriliği ve fetal/yeni doğan mortalitesini işaret etmektedir. Mevcut araştırmalar, gebelik döneminde maruz kalınan şiddet ile besin güvencesi, malnütrisyon, yetersiz doğum öncesi bakım, erken doğum ve düşük doğum ağırlı̆̆1 gibi olumsuz sonuçların ilişkili olduğunu göstermektedir. Ayrıca, gebelikte şiddet gören anneler ve çocuklarıyla yapılan çalışmalarda, çocukların gelişimsel, sosyo-duygusal ve davranışsal problemler açısından daha fazla risk altında olduğu gösterilmektedir. Farklı ülkelerde yapılan çalışmalarda yakın eş şiddetinin yüksek prevalansına rağmen, şiddete maruz kalan annelerden doğan bebeklerin uzun dönem sonuçları yeterince araştırılmamıştır. Yakın eş şiddetinde azalma, sadece kadınların refahını ve sağlığını iyileştirmekle kalmaz, aynı zamanda çocuğun büyüme ve gelişimini de olumlu yönde etkiler. Bu derlemenin amacı, gebe kadınlara uygulanan şiddetin, gebelik ve emziklilik dönemlerinde, anne ve çocuğun sağlığı ile beslenmesine olan etkilerini tartışmaktır.

Anahtar kelimeler: Bebek, beslenme durumu, gebelik, şiddet, yakın eş şiddeti

\begin{abstract}
\footnotetext{
1. İletişim/Correspondence: Biruni Üniversitesi, Sağlık Bilimleri Fakültesi, Beslenme ve Diyetetik Bölümü, İstanbul, Türkiye

E-posta: asghar.amanpour@gmail.com • 둔tps://orcid.org/0000-0001-9783-691X

2. Biruni Üniversitesi, Sağlık Bilimleri Fakültesi, Beslenme ve Diyetetik Bölümü, İstanbul, Türkiye • (1) https://orcid.org/0000-0002-6938-6787
}

Although violence is at least as old as human history, it was not perceived as a serious problem, especially until the last century. However, violence, which is experienced increasingly every day for various reasons and has been almost settled in daily life, appears in all dimensions from individual violence to collective violence. More than one million people die owing to violence each year. Especially, if pregnancy is unplanned, it can be an important risk for domestic violence. Domestic violence during pregnancy is reported as a major public health problem, especially in low-income countries.
3. Biruni Üniversitesi, Sağlık Bilimleri Fakültesi, Beslenme ve Diyetetik Bölümü, İstanbul, Türkiye • (1) https://orcid.org/0000-0002-5702-9563

4. Biruni Üniversitesi, Sağlık Bilimleri Fakültesi, Beslenme ve Diyetetik Bölümü, İstanbul, Türkiye - 으 https://orcid.org/0000-0002-7553-8687 
Intimate partner violence during pregnancy is closely related to nutrition and health problems in mother and child during pregnancy and lactation. During pregnancy, reports indicate some medical problems in addition to obstetric complications, psychological problems, premature birth, fetal growth restriction, and fetal or neonatal mortality. Current studies suggest that violence during pregnancy is associated with negative consequences such as food security, malnutrition, inadequate prenatal care, preterm delivery and low birth weight. Moreover, studies conducted with mothers and their children exposed to violence during pregnancy show that children are at greater risk for developmental, socio-emotional and behavioral problems. Despite the high prevalence of intimate partner violence in studies conducted in different countries, the long-term consequences of infants born to mothers exposed to violence have not been adequately investigated. The aim of this review is to examine the effects of domestic violence against pregnant women on the health and nutrition of the mother and child during pregnancy and lactation.

Keywords: Infant, nutritional status, pregnancy, violence, intimate partner violence

\section{GíRIŞ}

Dünya'nın neredeyse her toplumunda kadına yönelik şiddet uygulandığı görülmektedir. Toplumsal araştırmalar sonucunda dünya genelinde kadınların \%10-50'sinin hayatları boyunca en az bir kez partnerleri tarafından fiziksel şiddete maruz kaldığ Dünya Sağlık Örgütü'nün (DSÖ) 2002 yllı raporunda bildirilmiştir (1). Sadece kadına şiddet ya da aile içi şiddet olarak değil, yaşamın hemen her alanında görülmekte olan şiddet, bireyin ruh ve beden sağlığı açısından olduğu kadar, toplumsal açıdan da önemli bir tehdit olarak varlığını sürdürmektedir (2). "Kadına yönelik şiddet” kadınlara, sadece kadın oldukları için uygulanan veya kadınları etkileyen cinsiyete dayalı bir ayrımcılık ile kadının insan hakları ihlaline yol açan ve kanunda şiddet olarak tanımlanan her türlü tutum ve davranış olarak tanımlanmaktadır (3). Yaşamları boyunca herhangi bir dönem içerisinde şiddetle karşılaşılabildiği gibi gebelik süreci içerisinde de kadınlar şiddete maruz kalabilmektedir. Gebelik döneminde şiddet gören kadınlar, fiziksel sağlık sonuçları ile birlikte psikolojik bazı sorunlar açısından da olumsuz olarak etkilenmektedir. Bu sorunlar tedavi edilmezse, gebelik ve emziklilik dönemlerinde hem anne hem de çocuk üzerinde olumsuz sağlık sonuçlarına yol açabilir (4). Gebelikte şiddetin meydana getirdiği olumsuz sonuçların başında; erken doğum, düşük doğum ağırlığl, perinatal ve neonatal ölümler yer almaktadır (5). Düşük doğum ağırlıklı veya erken doğan bebeklerin, hem çocukluk hem de yetişkinlik çağında kardiyovasküler hastalıklar, solunum sistemi hastalıkları ve nöropsikiyatrik bozukluklar gibi çeşitli komorbiditeler açısından daha fazla riskli oldukları bilinmektedir. Bununla birlikte, erken doğum ile yetişkinlik dönemindeki mortalite ilişkisini araştıran yakın zamanlı bir sistematik derlemede, genetik ve çevresel faktörlerden bağımsız olarak, erken doğumun yetişkinlikte ılımlı düzeyde artan mortalite oranları ile ilişkili olduğu bildirilmiştir (6). Gebelikteki şiddet emziklilik dönemini de etkilemektedir. Emziklilik döneminde devam eden yakın eş şiddetinin çocuğa verilen bakım ve emzirmeyi sürdürme olasılıklarını azalttığı bildirilmektedir (7). Gebelikte şiddetin meydana getirdiği psikolojik sorunların başında maternal depresyon gelmektedir. Şiddet ile doğum sonrası depresyon arasındaki ilişkiyi inceleyen bir meta analiz, şiddet gören kadınlarda doğum sonrası depresyon riskinin önemli derecede daha yüksek olduğunu göstermiştir (8). Gebelikte şiddete bağlı olarak ortaya çıkan depresyon ve anksiyete gibi psikolojik sorunlar, doğum sonrası depresyon riskini artırarak anne-çocuk ilişkisi, emzirme dahil olmak üzere çocuğa verilen bakım ve dolayısıyla çocuğun büyüme ve gelişimi üzerine olumsuz etkiler göstermektedir (5). Doğum sonrası depresyon yaşayan annelerin, yenidoğanın ihtiyaçlarına daha az hassasiyet gösterdiği ve olumsuz davranışları ifade etme olasılıklarının daha yüksek olduğu bildirilmektedir. Bu durum, çocuğun bilişsel ve duygusal gelişimini olumsuz yönde etkilemektedir (8). Gebelikte depresyonun yetersiz 
vücut ağırlık kazanımı, erken doğum, düşük doğum ağırlığı, obstetrik komplikasyonlar ve postpartum depresyon gibi hem anneye hem de fetüse etki eden olumsuz sonuçlar ile ilişkili olduğu bildirilmiştir (9). Türkiye'de Kadına Yönelik Aile İçi Şiddet Araştırması 2014 raporuna göre, kadınların \%36’sı fiziksel, \%44’ü duygusal, \%12'si cinsel ve \%30'u ekonomik şiddetle karşı karşıyadır (10). Ulusal verilere göre, Türkiye'de gebe kadınlara yakın eş tarafından uygulanan fiziksel şiddetin görülme sıklığı ise \%8.3’tür (4). Dünya Sağlık Örgütü’nün (DSÖ) (11) çok uluslu yapılan çalışmasında, kadınların yaklaşık \%1-28'inin gebelik sırasında fiziksel şiddete maruz kaldığı bildirilmektedir. Yine DSÖ verilerine göre, gebelikte kadına yakını veya partneri tarafından uygulanan fiziksel şiddetin görülme sıklığı \%4-12 arasında değişmektedir (4). Farklı ülkelerde yapılan çalışmalarda yüksek yakın eş şiddeti prevalansına rağmen, şiddete maruz kalan annelerden doğan bebeklerin uzun dönem sonuçları yeterince araştırılmamıştır. Yakın eş şiddetinde azalma, sadece kadınların refahını ve sağlığını iyileştirmekle kalmaz, aynı zamanda çocuğun büyüme ve gelişimini de olumlu yönde etkiler. $\mathrm{Bu}$ derlemede, gebe kadınlara uygulanan şiddetin, gebelik ve emziklilik dönemlerinde, anne ve çocuğun sağlığı ile beslenmesine olan etkilerinin incelenmesi amaçlanmaktadır.

\section{Gebelikte Yeterli ve Dengeli Beslenmenin Önemi}

Gebelik döneminde yeterli ve dengeli beslenme, hem maternal hem de fetal sağlık üzerinde önemli etkilere sahiptir. Enerji ve besin ögesi gereksinimlerinin artış gösterdiği gebelik döneminde annenin yetersiz beslenmesi, yenidoğan üzerinde ylllarca devam eden etkilere sahiptir (12). Bu dönemde enerji, makro ve mikro besin ögelerinin yeterli şekilde sağlanması preeklampsi, gestasyonel diyabet, intrauterin gelişme geriliği ve erken doğum gibi problemlerin riskini azaltmaktadır. Gebelikte sağlıklı beslenme bebeğin yetişkinlik çağında kronik hastalıklardan korunmasında da oldukça etkilidir. Bu dönemde gebe kadının önerilenden daha az vücut ağırlığı kazanımı, düşük doğum ağırlıklı bebek riskini artırmaktadır
(13). Gebelikte yetersiz makro- ve mikro besin ögesi alımının, gebelik seyrinde olumsuz sonuçlar ve anormal prenatal gelişim ile ilişkili olduğu bilinmektedir. Özellikle, gebelikte gereksinimleri artan demir, kalsiyum, folik asit, magnezyum, D vitamini ve A vitamini gibi mikro besin ögelerinin yetersizlikleri önemli sağlık sorunlarına yol açmaktadır. Gebelik döneminde annenin beslenmesi, fetüsün vücut ağırlığı, boy uzunluğu ve fizyolojik yapısıyla ilgili olduğu kadar zihinsel gelişimiyle de ilişkilidir. Beyin yapısının şekillendiği ilk trimesterde annenin yetersiz beslenmesi, fetüsün mental gelişiminde kalıcı bir gerilik oluşturabilmektedir (14). Yetersiz beslenme, 1900'lü yıllarda ABD’li kadınlarda doğumun uzamasına, doğum esnasında kanamaya, düşük doğum ağırlıklı bebeklere ve spontan ölümler gibi olumsuz sonuçlara neden olmuştur. Günümüzde ise halen birçok gelişmekte olan ülkede, endişe verici koşullar nedeniyle aynı risklerden bahsedilmektedir (12). Şiddet ve beraberinde getirdiği fiziksel ve zihinsel sorunlar, aşırı veya yetersiz beslenme riskini artırabilecek faktörler arasındadır. Şiddete bağlı gelişen depresyon ve stres, kadınların daha az veya daha fazla besin tüketimine yol açarak zayıflık veya obeziteye neden olabilir. Bununla birlikte, yakın eş şiddeti kadınlarda sigara, alkol ve uyuşturucu kullanımı gibi olumsuz alışkanlıkları da tetikleyebilmektedir (15). Bazı durumlarda ise gebe kadınlar daha fazla yiyeceğe gereksinim duymaları ve yiyecek talep etmeleri nedeniyle şiddete maruz kalmakta ve bu nedenle de şiddetten kaçınmak için besin tüketim miktarlarını azaltabilmektedir. $\mathrm{Bu}$ durum, hem gebe kadının enerji ve besin ögesi gereksinimlerini yeterince sağlayamamasına hem de büyümekte olan fetüsün anneden optimal seviyede besin ögelerini karşılayamamasına yol açar. Bunun önlenmesi için besin güvencesinin sağlanmasına odaklanmak büyük önem taşımaktadır (16). Yapılan bir araştırmada, orta ve şiddetli düzeyde besin güvencesizliği bulunan hanelerde yaşayan gebe kadınların, besin güvencesi olan hanede yaşayan gebe kadınlara kıyasla yaklaşık 2-8 kata kadar daha yüksek prenatal depresif belirtiler gösterdiği, ayrıca yakın eş şiddetinin prenatal depresif semptomlar ile 
önemli derecede ilişkili olduğu belirlenmiştir (17). Besin güvencesizliği nedeniyle yetersiz beslenmeye bağlı olarak, enerji ve $B_{12}$ vitamini, selenyum, çinko, folik asit ve omega-3 yağ asitleri gibi spesifik besin ögelerinde meydana gelen eksikliklerin prenatal depresyon gibi psikolojik sorunları etkilediği bildirilmiştir (18). Gebelik döneminde olduğu gibi emziklilik dönemi de yenidoğanın sağlığı üzerinde oldukça önemlidir. Emzirme sırasındaki enerji ve besin ögesi gereksinimleri gebelik dönemine kıyasla daha fazladır. Anne sütünün içeriği hem annenin yedikleri hem de maternal depolardan sağlanmaktadır (12). Anne sütünün bebekte zihinsel ve duyusal gelişimi destekleme, alerjik hastalıklar ve enfeksiyonlardan korunma ve yetişkinlik çağında obezite, diyabet, kalp hastalıkları gibi kronik hastalıkların görülme olasılığını azaltma etkileri olduğu bilinmektedir (13). Gebelik ve emzirme dönemlerinde aşırı derecede yetersiz beslenen annelerin anne sütünde bazı besin ögelerinin eksik olabileceği gösterilmiştir (12). Bu dönemlerde şiddete bağlı olarak gelişen psikolojik sorunların etkisiyle, annenin yenidoğanın ihtiyaçlarına daha az hassasiyet gösterdiği, anne çocuk ilişkisinin daha düşük olduğu, annelerin olumsuz davranışları ifade etme olasılıklarının daha yüksek olduğu bildirilmektedir (8). Bunun yanı sıra, emziklilik döneminde yakın eş şiddetine maruz kalan annelerin emzirmeyi sürdürme olasılıklarının daha az olduğu bildirilmiştir (7).

\section{Kadına Yönelik Şiddet}

Kadına yönelik şiddet; kadını inciten, kadına zarar veren ve cinsiyete dayanan, fiziksel, ruhsal ve cinsel hasarla sonuçlanma olasılığı bulunan, özel yaşamında veya toplum içerisinde kadına baskı uygulanması ve özgürlüklerinin kısıtlanmasına yol açan davranışlar olarak tanımlanmaktadır (19). Birleşmiş Milletler'in "Kadınlara Yönelik Şiddetin Önlenmesi” bildirgesinde ise "özel yaşamda veya kamusal yaşamda meydana gelmesi fark etmeksizin, kadınlara fiziksel, psikolojik veya cinsel istırap ve acı veren veya verebilecek olan, cinsiyete dayanan bir eylem veya bu tür eylemlerle tehdit etme, zorlama veya keyfi olarak özgürlükten yoksun bırakma” şeklinde tanımlanmaktadır (20). Bildirgede ev içi şiddet, özel yaşamda, genellikle cinsel ilişki ya da kan bağıyla birbirine bağlı kişiler arasında gerçekleşen şiddet şekli olarak ele alınmaktadır (21). Özellikle erkeklerin kadınlardan daha üstün görüldüğü, cinsiyete özgü rollerin net çizgilerle ayrıldığı toplumlarda kadına yönelik şiddetin daha sık meydana geldiği bildirilmektedir (22). Arkeologlar tarafından yapılan bir araştırmada, kadınların fiziksel şiddete maruz kalma kökeninin 3000 yl öncesine dayandığı belirtilmiştir. Erkek mumyaların kemiklerinde \%9-20 kırıkla karşılaşılmışken, kadın mumyalarda bu oran \%30-50’ye kadar ulaşmıştır. Eski Roma yazıtlarında ise kendilerinden izinsiz oyunlara katıldıkları veya zina yaptıkları için erkeklerin eşlerini cezalandırma, boşama veya öldürme hakkına sahip olduklarının yazılı olduğu belirlenmiştir (23). Son dönemde kadınların maruz kaldığı en yaygın şiddet şeklinin aile içi şiddet olduğu DSÖ başta olmak üzere birçok kuruluş tarafından vurgulanmaktadır (24). Dünya Sağlık Örgütü’nün 2005 raporunda kadına yönelik şiddetin önlenmesi adına, cinsiyet eşitliğinin ve kadınların insan haklarının teşviki, şiddete karşı çok sektörlü eylem planlarının oluşturulması ve takibi, yakın eş şiddetinin önlenmesine yönelik programların geliştirilmesi, çocuk cinsel istismarının önlenmesine öncelik verilmesi ve fiziksel ortamların daha güvenli hale getirilmesi gibi çok sayıda öneri mevcuttur (25). Birleşmiş Milletler üye ülkelerinin 2030 yllına kadar sürecek olan Sürdürülebilir Kalkınma Hedefleri içerisinde de şiddetin önlenmesi adına cinsiyet eşitliğini sağlamak ve tüm kadınlar ile kız çocuklarını güçlendirmek amacıyla çeşitli hedefler belirlenmiştir (26).

\section{Gebelik Döneminde Kadına Yönelik Şiddet}

Dünya üzerinde doğurganlık çağındaki kadınların \%13-61'inin eşleri tarafindan şiddet gördüğü tahmin edilmektedir. Dünya Sağllk Örgütü’nün küresel istatistiklerine göre, kadınların yaklaşık \%1-28’i gebelik sırasında fiziksel şiddete maruz kalmıştır 
(11). Bununla birlikte, gebelikte görülen yakın veya eş tarafından uygulanan fiziksel şiddetin görülme sıklığı dünya üzerinde \%4-12 arasında değişirken, ulusal verilere göre ülkemizdeki oran \%8.3’tür (4). Yapılan bir meta analiz çalışmasında, 23 ülkeden elde edilen verilere göre gebelikte yakın eş şiddeti \%19.8 olarak tahmin edilmektedir ve düşük-orta gelirli ülkelerde (Bangladeş, Uganda gibi) görülme sıklığı \%12 ile \%57 arasında değişmektedir. Yakın eş şiddetini etkileyen faktörler arasında yoksulluk, sosyal çevre, bebeğin cinsiyeti ve sağlık durumu, travmatik olaylara maruz kalma, gebeliğin planlanmamış olması gibi durumlar yer almaktadır (5). Bununla birlikte, öğrenim ve refah seviyesinin gebelikteki şiddet oranını etkilediği bilinmektedir. Öğrenim seviyesi üniversite ve üzeri olan kadınlar gebelik döneminde şiddete daha az maruz kalırken, öğrenim düzeyi düşük olan veya öğrenim görmeyen kadınlar şiddete daha fazla maruz kalmaktadır (10). Bu durumda özellikle adölesan gebeliklerde şiddet riski daha da artmaktadır. Adölesan gebeler, aile içi şiddetin yanı sıra hemcinsleri tarafindan yapılan şiddete de sıklıkla maruz kalmaktadır (27). Gebelik öncesinde de şiddete maruz kalma veya prenatal bakımının yetersiz olması, yine gebelik esnasında aile içi şiddet riskini artıran durumlardandır. Gebelikte şiddete maruz kalmanın, preeklampsi ve gestasyonel diyabet gibi sağlık problemlerinin daha sık görülmesi ile ilişkili olduğu belirtilmektedir. Gebelik öncesinde ve gebelik dönemindeki şiddet; idrar yolu enfeksiyonları, vajinal kanama, madde kullanımının artışı ve erken doğumlar gibi genel sağlık durumunu etkileyen olumsuz sonuçlara yol açabilir (27-29). Ne yazık ki, Türkiye'de de kadına yönelik aile içi şiddet, yaygın ve ciddi bir toplumsal problemdir. Yapılan bir araştırmada, evli kadınların \%36'sının fiziksel, \%12'sinin cinsel şiddet gördüğü, bununla birlikte, 18 yaşından sonra evlenen kadınların \%42'sinin psikolojik, \%30'unun ise ekonomik şiddet ile karşı karşıya kaldığı bildirilmiştir (30). Ayrancı ve ark. (31) tarafindan 154 gebe kadın ile yürütülen bir çalışmada, kadınların \%71'inin gebeliği süresince aile içi şiddet gördüğü belirlenmiştir.

\section{Gebelik Döneminde Şiddetin Maternal/Fetal Sağlığa ve Beslenmeye Etkileri}

Gebelik döneminde annenin maruz kaldığı şiddetin anne ve bebeğin sağlığı için olumsuz sonuçlara yol açtığı bilinmektedir. Yapılan araştırmalar, gebelik dönemindeki şiddet ile annenin düşük vücut ağırlığı kazanımı, malnütrisyon, yetersiz doğum öncesi bakım, erken doğum ve düşük doğum ağırlığ gibi olumsuz doğum sonuçlarının ilişkili olduğunu göstermektedir $(32,33)$. Doğum ağırlığı, bebeğin büyümesi ve hayatta kalmasının önemli bir göstergesidir ve bebeğin erken mortalitesi ve morbiditesi ile ilişkilidir. Özellikle düşük gelirli ülkelerde, gebelik sırasında aile içi şiddet, düşük doğum ağırlıklı bebeklerin doğmasının ana nedenlerinden biridir (34). Aile içi şiddet gören gebe kadınlar, kendilerine yönelik risklere ek olarak, yetersiz doğum öncesi bakım, riskli davranışların daha yüksek insidansı, doğrudan fiziksel travma, stres ve ihmal gibi olumsuz sonuçlar açısından da risk altındadır (35). Yakın eş şiddetine maruz kalan kadınların gebeliksonrasıilk6 ayiçerisinde emzirmeye başlama ve önerilen emzirme yöntemlerini uygulama oranlarının azaldığı da bildirilmektedir (36).

Gebelik sırasında uygulanan şiddet; annenin, fetüsün veya her ikisinin birden travmaya bağlı ortaya çıkan sağlık sorunları veya ölüm riskine yönelik bir tehdittir. Gebelikte fiziksel şiddet; AIDS ve diğer cinsel yolla bulaşan hastalıklar, idrar yolu enfeksiyonları, madde kullanımı, depresyon ve diğer ruh sağlığı belirtileri gibi gebelik sırasındaki sağlık sorunları ile ilişkilidir. Amerika Birleşik Devletleri’nde yapılan bir çalışmada, fetal ölümün bir başka sebebi olan elektif gebeliğin sonlandırılmasının da yakın eş şiddetiyle ilişkili olduğu bulunmuştur (32). Şiddete bağlı fiziksel ve psikolojik etkiler sonucunda, annenin gebelik döneminde yetersiz beslenmesi, fetüsün vücut ağırlığı ve boy uzunluğu üzerinde olumsuz etkiler göstermektedir. Liberya'da anneleri cinsel yakın eş şiddetine maruz kalmış çocukların ortalama boyagöre-ağırlık-z-skorlarının daha düşük olduğu ve diğer çocuklara göre bodur olma olasılıklarının daha yüksek olduğu belirlenmiştir (37). Yakın eş şiddetinin büyüme 
ve gelişme üzerindeki olumsuz etkileri dışında bilişsel gelişim ile ilişkisini ortaya koyan çalışmalar da mevcuttur. Yapılan toplum temelli bir kohort çalışmasında 3153 anne-çocuk çifti için yakın eş şiddeti ile çocuklardaki zeka düzeyi (intelligence quotientIQ) puanları arasındaki ilişkiler incelenmiştir. Mevcut çalışma, gebelikte fiziksel olarak yakın eş şiddetine maruz kalan annelerden doğan çocukların IQ puanlarının olumsuz yönde etkilenebileceğini göstermektedir. Doğum sonrası fiziksel şiddete maruz kalan annelerden doğan çocukların IQ puanlarının, şiddete maruz kalmayan annelerin çocuklarınkinden daha düşük olduğu saptanmıştır (38). Güney Asya bölgesinden Bangladeş, Hindistan ve Nepal'de yapılan çalışmada; fiziksel şiddet, cinsel şiddet veya her ikisinin de yaşandığı annelerin çocuklarında akut solunum yolu enfeksiyonu, yüksek ateş ve diyarenin daha yüksek görüldüğü ortaya konmuştur. $\mathrm{Bu}$ durumlar aynı zamanda çocukluk çağında malnütrisyon gelişimi için de bir risk oluşturmaktadır (39). Hindistan'da aile içi şiddet gören kadınlar ve beslenme durumları arasındaki ilişkiye yönelik yapılan bir araştırmada, doğurganlık çağındaki 69.072 kadın ve 12-35 aylık 14.552 çocuktan elde edilen veriler analiz edilmiştir. Kadınların yaklaşık \%19'unun aile içi şiddet yaşadığı bildirilmiştir. Yakın eş şiddetine maruz kalan kadınların yüksek oranda beslenme bozukluğu yaşadığı, yaklaşık yarısında anemi bulunduğu ve yaklaşık üçte birinde ise malnütrisyon olduğu bildirilmiştir. Çocukların ise \%70'inde anemi olduğu, yarısından fazlasının bodur, \%43’ünün aşırı zayıf, \%16’sının yaşına göre zayıf ve \%12'sinin yaşına göre düşük beden kütle indeksine sahip olduğu belirtilmiştir (40).

\section{SONUÇ VE ÖNERILLER}

Gebelikte görülen yakın eş şiddeti, gebelikle ilişkili bazı sağlık sorunları ile birlikte erken doğum, düşük doğum ağırlığı, fetal büyüme geriliği, fetal ve neonatal ölüm gibi olumsuz sonuçları beraberinde getirmektedir. Özellikle öğrenim düzeyinin ve gelir seviyesinin düşük olduğu bölgelerde veya adölesan gebeliklerde, şiddet oranının artışı başta yetersiz beslenme olmak üzere pek çok beslenme ve sağlık sorunlarını da beraberinde getirmektedir. Gebelik döneminde yakın eş şiddeti gören kadınlar, gebelik sonrası dönemde de bu durumla karşı karşıyadır. Şiddetin meydana getirdiği başta depresyon ve anksiyete gibi psikolojik problemler, doğum sonrası dönemde de devam ederek annenin laktasyon döneminde artan gereksinimlerini yeterince karşılayamamasına, erken dönemde emzirmeye başlayamamasına ve bebeğin anne sütünden optimal düzeyde faydalanamamasına yol açmaktadır. Oysa, anne sütünün bebekte zihinsel ve duyusal gelişimi destekleme, alerjik hastalıklar ve enfeksiyonlardan korunma, yetişkinlik çağında obezite, diyabet, kalp hastalıkları gibi kronik hastalıkların görülme olasılığını azaltma gibi oldukça büyük etkileri vardır. Kadına yönelik şiddetin önlenmesi için, cinsiyet eşitliğinin ve kadınların insan haklarının teşviki, şiddete karşı çok sektörlü eylem planlarının oluşturulması ve takibi, yakın eş şiddetinin önlenmesine yönelik programların geliştirilmesi, çocuk cinsel istismarının önlenmesine öncelik verilmesi ve kadınlara besin güvencesinin sağlanmasına odaklanılması ön plana çıkarılmalıdır. Kadına yönelik şiddetin azalması, yalnızca kadınların refahını ve sağlığını iyileştirmekle kalmaz, aynı zamanda çocuğun büyüme ve gelişimini de olumlu yönde etkileyerek daha sağlıklı nesillerin yetişmesini sağlar.

Çıkar çatışması - Conflict of interest: Yazarlar çıkar çatışması olmadığını beyan ederler. - The authors declare that they have no conflict of interest.

\section{KAYNAKLAR}

1. World Health Organization. The world health report: Reducing risks, promoting healthy life. Geneva: World Health Organization; 2002. 230 p.

2. Krug EG, Mercy JA, Dahlberg LL, Zwi A. The world report on violence and health. Lancet. 2002;360:1083-88.

3. Şenol Ercoşkun HK. Ailenin korunması ve kadına karşı şiddetin önlenmesine dair kanun üzerine bir inceleme. Uyuşmazlık Mahkemesi Dergisi. 2019;0(13):423-59.

4. Topkara FN, Özerdoğan N. Gebelikte eş şiddeti; maternal, fetal ve neonatal sağlık üzerindeki etkileri. Türkiye Klinikleri Sağlık Bilimleri Dergisi. 2020;5(1):150-6. 
5. Halim N, Beard J, Mesic A, Patel A, Henderson D, Hibberd P. Intimate partner violence during pregnancy and perinatal mental disorders in low and lower middle income countries: A systematic review of literature, 1990-2017. Clin Psychol Review. 2018;66:117-35.

6. Crump C. Preterm birth and mortality in adulthood: A systematic review. J Perinatol. 2020;40:833-43.

7. Scheid CR, Paulson JL, Miller-Graff LE. Feelings and feedings: Psychopathology and breastfeeding attitudes in women with a history of intimate partner violence. Psychol Trauma. 2020.

8. Wu Q, Chen HL, Xu XJ. Violence as a risk factor for postpartum depression in mothers: A meta-analysis. Arch Womens Ment Health. 2012;15:107-14.

9. Chen X, Zhao D, Mao X, Xia Y, Baker PN, Zhang H. Maternal dietary patterns and pregnancy outcome. Nutrients. 2016;8(6):351.

10. Hacettepe Üniversitesi Nüfus Etütleri Enstitüsü. Türkiye'de kadına yönelik aile içi şiddet araştırması. Ankara: Elma Teknik Basım Matbaacılık; 2015, s. 547.

11. World Health Organization. Responding to intimate partner violence and sexual violence against women. 2013: p. 68.

12. Cox JT, Carney VH. Nutrition for Reproductive Health and Lactation. In: Mahan LK, Raymond JL, editors. Krause's Food \& The Nutrition Care Process. 14th ed. Canada: Elsevier. 2017:249.

13. Türkiye Beslenme Rehberi TÜBER 2015, T.C. Sağllk Bakanlığı Yayın No:1031, Ankara, 2016.

14. Arlı M, Şanlıer N, Küçükkömürler S, Yaman M. Anne ve çocuk beslenmesi. Pegem Atıf İndeksi. 2017:1-233.

15. Adhikari RP, Yogi S, Acharya A, Cunningham K. Intimate partner violence and nutritional status among nepalese women: An investigation of associations. BMC Womens Health. 2020;20(127):1-11.

16. Lentz E C. Complicating narratives of women's food and nutrition insecurity: Domestic violence in rural Bangladesh. World Development. 2018;104: 271-280.

17. Woldetensay YK, Belachew T, Biesalskli HK, Ghosh S, Lacruz ME, Scherbaum V. et al. The role of nutrition, intimate partner violence and social support in prenatal depressive symptoms in rural Ethiopia: Community based birth cohort study. BMC Pregnancy Childbirth. 2018:18(374);1-10.

18. Gebreyesus SH, Endris BS, Hanlon C, Lindtjorn B. Maternal depression symptoms are highly prevalent among food-insecure households in Ethiopia. Public Health Nutr. 2017:21(5);849-56.

19. Eryılmaz G. Aile içi şiddet, kadın sağlığı ve hemşirelik. Cumhuriyet Üniversitesi Hemşirelik Yüksekokulu Dergisi. 2001;5(2):19-24.
20. Joachim J. Shaping the human rights agenda: The case of violence against women. Gender Politics in Global Governance. 1999;4:142-160.

21. Sallan Gül S. Türkiye'de kadın sığınmaevleri erkek şiddetinden uzak yaşama açılan kapılar mı? Bağlam Yayınları. 2013;1.

22. Page AZ, İnce M. Aile içi şiddet konusunda bir derleme. Türk Psikoloji Yazıları. 2008;11(22): 81-94.

23. Dişsiz M, Şahin NH. Evrensel bir kadın sağlığı sorunu: Kadına yönelik şiddet. Maltepe Üniversitesi Hemşirelik Bilim ve Sanatı Dergisi. 2008;1(1):50-8.

24. Güler N, Tel H, Tuncay FÖ. Kadının aile içinde yaşanan şiddete bakışı. CÜ Tıp Fakültesi Dergisi. 2005;27(2):51-6.

25. World Health Organization. WHO multi-country study on women's health and domestic violence against women: Summary report of initial results on prevalence, health outcomes and women's responses. Genava: World Health Organization; 2005:22.

26. United Nations. The sustainable development goals report. United States of America: United Nations; 2019:32-33.

27. Silverman JG, Decker MR, Reed E, Raj A. Intimate partner violence victimization prior to and during pregnancy among women residing in 26 US states: Associations with maternal and neonatal health. Am J Obstet Gynecol. 2006;195(1):140-8.

28. McCloskey LA, Lichter E, Ganz ML, Williams CM, Gerber $\mathrm{MR}$, Sege $\mathrm{R}$ et al. Intimate partner violence and patient screening across medical specialties. Acad Emerg Med. 2005;12(8): 712-22.

29. Rodrigues T, Rocha L, Barros H. Physical abuse during pregnancy and preterm delivery. Am J Obstet Gynecol. 2008; 198(2):171-e1.

30. Aşkın EÖ, Aşkın U. Kadına yönelik aile içi şiddet ve yoksulluk ilişkisi: Aile içi şiddet mağduru kadınlar üzerine bir araştırma. Kapadokya Akademik Bakış. 2017;1(2):16-37.

31. Ayrancı Ü, Günay Y, Ünlüoğlu I. Hamilelikte aile içi eş şiddeti: Birinci basamak sağlık kurumuna başvuran kadınlar arasında bir araştırma. Anadolu Psikiyatri Dergisi. 2002;3(2):75.

32. Campbell JC. Health consequences of intimate partner violence. Lancet. 2002;359(9314):1331-6.

33. Alhusen JL, Ray E, Sharps P, Bullock L. Intimate partner violence during pregnancy: Maternal and neonatal outcomes. J Womens Health. 2015;24(1):100-6.

34. Bhandari, B. Domestic violence during pregnancy and it's effects on birth weight: perspective from Nepal. In: Lammi-Keefe CJ, Couch SC, Philipson E. Handbook of Nutrition and Pregnancy. 2nd ed. Humana Press; 2018. p.423-433. 
35. Shah PS, Shah J. Maternal exposure to domestic violence and pregnancy and birth outcomes: A systematic review and meta-analyses. J Womens Health. 2010;19(11):201731.

36. Caleyachetty R, Uthman OA, Bekele HN, MartínCañavate R, Marais D, Coles J. et al. Maternal exposure to intimate partner violence and breastfeeding practices in 51 low-income and middle-income countries: A population-based cross-sectional study. PLoS Medicine. 2019;16(10):1-15.

37. Chai J, Fink G, Kaaya S, Danaei G, Fawzi W, Ezzati M. et al. Association between intimate partner violence and poor child growth: results from 42 demographic and health surveys. Bulletin of the World Health Organization. 2016;94(5):331.

38. Abel KM, Heuvelman H, Rai D, Timpson NJ, Sarginson J, Shallcross R. et al. Intelligence in offspring born to women exposed to intimate partner violence: A population-based cohort study. Wellcome Open Res. 2019;4:1-15.

39. Ferdousy EZ, Matin MA. Association between intimate partner violence and child morbidity in South Asia. J Health Popul Nutr. 2015;33(1):16.

40. Ackerson LK, Subramanian SV. Domestic violence and chronic malnutrition among women and children in India. Am J Epidemiol. 2008;167(10):1188-96. 